\title{
Um modelo de fluxo para design de livro digital infantil
}

A flow model for children's digital book design

\author{
Deglaucy Jorge Teixeira \\ Universidade Federal de Santa Catarina, Brasil \\ deglaucyjorge@gmail.com \\ Bruna Bertolazi Maritan \\ Universidade Federal de Santa Catarina, Brasil \\ brunabertolazi@gmail.com
}

\author{
Berenice S. Gonçalves \\ Universidade Federal de Santa Catarina, Brasil \\ berenice@cce.ufsc.br
}

\begin{abstract}
The fundamentals of traditional publishing design are insufficient to support the children's book app design - book application format that brings a similar layout to printed picturebook and interactivities that resemble video games. So, how to structure your design process? And what approaches able to involve multimedia and interactivity to guide this design process? Through an exploratory, analytical and comparative research, we investigated graphic design and editorial theories, hypermedia design and game design. It was elaborated a proposal flow for digital children's book design.
\end{abstract}

Keywords: Children's book apps; Design; Process.

\section{Introdução}

A integração entre mídia impressa e digital trouxe oportunidades para 0 design associado às tecnologias portáteis.

O lançamento do iPad em 2010 marcou o início de novas formas de acesso a leitura, de maneira mais democrática e com distribuição facilitada, sendo mais acessível não só aos leitores, mas também às pequenas editoras e autores independentes. A popularização de dispositivos portáteis como smartphones, tablets e e-readers demanda publicações em formatos específicos, tais como apps (aplicativos) e ebooks (livros em formatos digitais).

Estas novas tecnologias utilizadas para leitura necessitam de adaptações do design editorial em seu processo produtivo, tendo em vista as diferentes mídias e a interatividade junto ao design do livro, herança do formato impresso.

O book app, livro em formato aplicativo (software), devido a possibilidade de agregar multimídia e interatividade tornou-se um tipo de ebook mais atrativo para o público infantil. Este formato traz um layout similar aos livros ilustrados tradicionais e apelos interativos que se assemelham aos videogames.

Diante deste contexto, surge a necessidade de elaboração de um outro escopo de conhecimentos para dar sustentação ao design do livro digital infantil, pois só os fundamentos do design editorial tradicional são insuficientes. Nesse sentido, esta pesquisa buscou responder as seguintes questões: como estruturar um processo de design para o livro digital infantil? $E$ quais as abordagens capazes de envolver multimídia e interatividade a fim de orientar seu processo de design?
Por meio de uma pesquisa exploratória, analítica e comparativa, investigou-se três fundamentos de design que se relacionam diretamente com o livro infantil em formato digital interativo, a saber: design gráfico e editorial (AMBROSE E HARRIS, 2011; HASLAM, 2007), considerando a herança do design de livro impresso; design de hipermídia pelo ponto de vista da experiência do usuário (GARRET, 2011), considerando o formato de livro digital como uma multimídia interativa; e design de games (FULLERTON, 2014; ADAMS, 2013 e CHANDLER, 2012), ao considerar o book app infantil como uma narrativa digital em formato de aplicativo com características similares aos videogames.

\section{Design do livro infantil}

Ao longo de sua existência, o livro vem sofrendo mudanças decorrentes das tecnologia disponíveis em cada época de sua existência. Segundo Chartier (1998), por mais que o livro se apresente em formatos diferentes seu objetivo principal é transmitir informação. Diante disso, o trabalho do designer de livro é tornar estas informações claras para o leitor (HENDEL, 2003).

O design do livro infantil, na categoria de livro ilustrado, onde a imagem é predominante em relação ao texto, existem variações de tamanhos, cores, ilustrações, suportes e tecnologia de impressão. E, acima de tudo, todos estes elementos que compõem o projeto gráfico devem ser criteriosamente concebidos em uma unidade, pois todas suas características são fundamentais para compreensão do conteúdo (TEIXEIRA, 2015).

Em um livro tradicional (impresso), o design é responsável pela composição estética e formal. Envolvendo escolhas do tamanho, do substrato, tipografia, organização do conteúdo e cores (ARAÚJO, 2008). 
O estudo do design do livro, independente do tema ou público-alvo, está dentro da área do design editorial, que utiliza métodos consagrados da grande áreas do Design Gráfico, organizado em um fluxo de etapas (AMBROSE e HARRIS, 2011). Entretanto, a partir das abordagens do design gráfico, Haslam (2007) propõe um processo direcionado para o design do livro. Processo este, já utilizado por designers em projetos voltados especificamente para produção de livros, classificado em quatro categorias, a saber: Documentação, Análise, Conceito e Expressão. Essas categorias não são mutuamente excludentes e um livro pode incluir diferentes elementos de cada categoria, sendo que, parte deste processo não pode ser definido por uma análise prática por ser peculiar a cada designer. De acordo com Haslam (2007), o "design é uma mistura de decisões racionais e conscientes que podem ser analisadas e decisões subconscientes que não podem ser deliberadas tão prontamente, uma vez que derivam da experiência e da criatividade do designer" (HASLAM, 2007, p. 23).

A primeira categoria, Documentação, organiza-se o conteúdo original do livro e informações que serão manipulados.

A segunda categoria, Análise, busca encontrar um padrão visual para classificar vários elementos ao analisar a estrutura e o conteúdo do livro. Nesta etapa existe uma forte interação entre o autor e o designer (e/ou editor).

A terceira categoria, Expressão, busca envolver e posicionar o leitor ao conteúdo por meios dos elementos de design, tais como cor, tipografia, imagens dentre outros que compõem o design gráfico.

A quarta categoria, Conceito, procura desenvolver a ideia essencial que visa reter a mensagem por meio de trocadilhos, paradoxos, clichês, metáforas e alegorias.

Diante destas etapas é importante que o designer adquira uma visão geral do conteúdo da obra ao reunir as informações iniciais em um briefing sem que, no entanto, necessite se especializar neste conteúdo.

Partindo do briefing, na perspectiva do design gráfico, Ambrose e Harris (2011), organizaram o processo de design gráfico e editorial em sete etapas, a saber: Definir, Pesquisar, Gerar ideias, Testar protótipos, Selecionar, Implementar e Aprender (Figura 1).

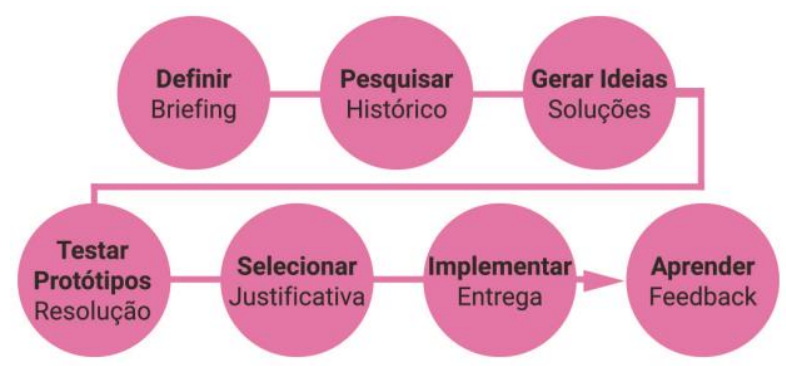

Figura 1: Etapas do Design gráfico. Fonte: Elaborada pelos autores a partir de Ambrose e Harris (2011).
Apesar de indicar este processo em forma linear os autores defendem a iterativo, pois é necessário retomar etapas anteriores quando for necessário fazer alguma adequação.

A primeira etapa, Definir, visa estruturar um briefing por meio dos objetivos do projeto, definição do problema de design e o público-alvo.

A segunda etapa, Pesquisar, busca reunir conteúdos para que façam sentido na composição da etapa seguinte, a etapa de Geração de Ideias. Nesta etapa o designer foca nas informações coletadas na pesquisa junto as restrições e objetivos do projeto para em seguida desenvolver um protótipo como possível solução, chegando assim na etapa de Testar Protótipos.

Em seguida, após testes de possíveis soluções, a próxima etapa, Selecionar, visa escolher a melhor e mais viável solução de acordo com o escopo do briefing, com os custos e com o tempo disponível para execução.

Na próxima etapa, Implementar, a solução escolhida é finalizada e preparada para entregar aos responsáveis pela produção final.

Ambrose e Harris (2011), sugere que a ultima etapa, Aprender, aconteça ao longo do processo, concomitante com as demais etapas, pois trata-se do retorno e aceitação do público-alvo e do pessoal envolvido no processo. Este feedback é capaz de gerar novas oportunidades e aprendizado para projetos futuros.

\section{Design do livro Digital infantil}

Assim como várias modalidades de informação e veículos comunicação midiáticos estão mudando em decorrência das novas tecnologias, a literatura também não está imune aos avanços tecnológicos. De acordo com Baliza (2014) seria quase impossível que as novas mídias não desencadeassem mudanças perceptíveis no campo literário, tais como dispositivos ficcionais hipertextuais, autopublicação, publicações colaborativas e participativas, distribuição de conteúdo via streaming e principalmente os ebooks (livros digitais).

No caso dos livros digitais infantis, os book apps - ebooks em formato aplicativo, ou seja, softwares, por se tratar de uma hipermídia, comportam uma maior carga de multimídia e interatividade. Estes aplicativos, além das diferentes mídias como texto escrito, imagem, animação e som, utilizam narrativas mais complexas com adição de games e atividades lúdicas no fluxo da história (TEIXEIRA, 2015).

Para estudar o design deste formato de livro, é fundamental que se entenda o processo de design de uma hipermídia linguagem da era digital composta por informações híbridas e multimídia capaz de serem associadas por meio de ações interativas do usuário (SANTAELLA, 2013). 
Apoiado em pesquisas direcionadas a experiência do usuário, ou seja, que buscam identificar como um produto funciona no mundo real e em contato com o usuário, Garrett (2011), em seus estudos da hipermídia em forma de web e aplicativos, propõe cinco planos divididos ao meio. De um lado traz o enfoque do produto como funcionalidade e do outro como informação. O objetivo dos planos é a satisfação e a construção de uma boa experiência para usuário. Os planos são: Plano de Superfície, Plano de Esqueleto, Plano de Estrutura, Plano de Escopo e Plano de Estratégia (Figura 2).

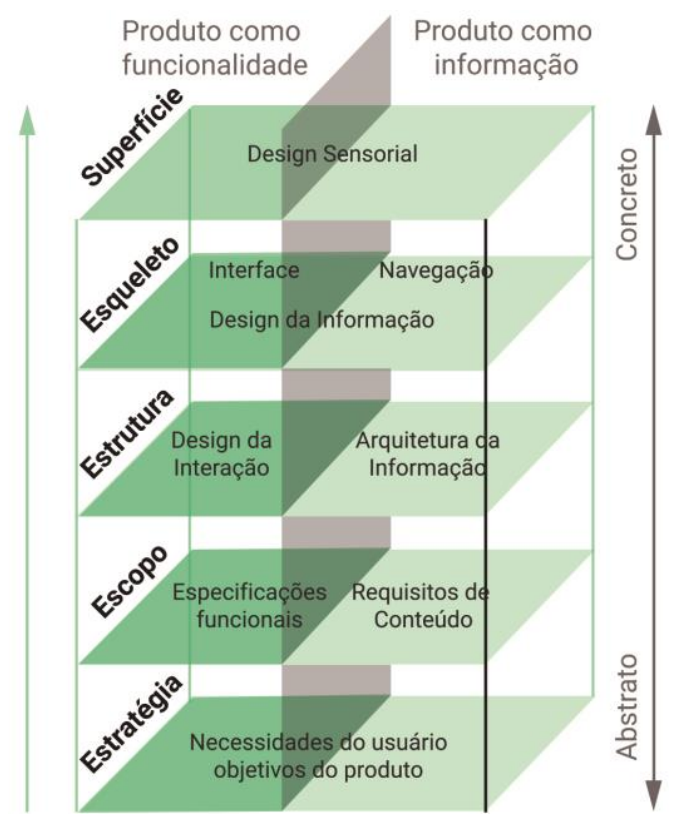

Figura 2: Metodologia design de Hipermídia com foco na experiência do usuário. Fonte: Elaborada pelos autores a partir de Garrett (2011).

Do lado das funcionalidades a maior preocupação é a execução das tarefas, os passos envolvidos na tarefa e como o público irá entende-la. No lado oposto pensa-se em como a informação será apresentada e o que isso significa para os usuários. Capacitar as pessoas para encontrar, absorver e fazer sentido sobre a informação que se está disponibilizando. (GARRETT, 2011)

O Plano Escopo, é fundamentado na estratégia. Engloba, não apenas a motivação para acessar o produto, mas o que o usuário busca e espera dele. As necessidades do usuário são os objetivos do design em relação ao produto. Por outro lado, há as necessidades do projeto, de mercado, de custos, de funcionalidades e informações necessárias.

O Plano Estrutura define como as várias funcionalidades se combinarão. Essas funcionalidades são definidas no plano de escopo do produto, de acordo com o contexto do projeto. Cabe, neste plano, as especificações funcionais, descrição do conjunto de recursos em forma de requisitos de conteúdo e descrição dos vários elementos necessários ao projeto.
O Plano Esqueleto é a expressão concreta da estrutura mais abstrata do produto. Este plano define a localização dos elementos na navegação, enquanto a estrutura define como os usuários chegarão até esses elementos e quais serão esses elementos. Trata-se do design de interação, isto é, como o sistema deve se comportar de acordo com o usuário, além da arquitetura da informação e arranjo dos elementos para melhor entendimento do usuário. É neste plano que os botões, controles, imagens, texto estão arranjados. Estes elementos devem ser estruturado para permitir a máxima eficiência e eficácia da interação. Assim, eles são facilmente encontrados e pode-se achar o que se precisa com maior facilidade e entendimento. O Plano Esqueleto é dividido em três componentes: design da informação, para facilitar seu entendimento, design de interface, elementos da interface que permitem que o usuário interaja com as funcionalidades do sistema. No Design de navegação, o conjunto de elementos estão disponíveis na tela para que o usuário possa navegar pela arquitetura da informação.

O Plano Superfície é a parte visível ao usuário, onde ocorre a interação. São as webpages ou telas iniciais, compostas por texto e imagens com algumas áreas clicáveis. A ênfase está a experiência sensorial. Alguns designers costumam pensar separadamente nos lados deste plano.

Todos estes planos resultam em frames conceituais para atender as necessidades da experiência do usuário e definir as ferramentas necessárias para isso. A cada plano o projeto fica menos abstrato e mais concreto. No primeiro plano, na base da figura 2, a forma de um site não seria tão preocupante, mas em como ele iria se encaixar nas estratégias do projeto e nas necessidades do usuário. No último plano a preocupação são os detalhes concretos da aparência. A cada plano as decisões tornam-se mais específicas e mais detalhadas, pois são limitadas pelas definições feitas no plano anterior (GARRETT, 2011).

Cabe destacar que ocorre uma dependência em relação aos planos nos dois sentidos. Decisões em planos acima podem surgir da reavaliação de decisões tomadas em planos abaixo. As decisões podem ter efeito cascata em ambas as direções. Além disso, o trabalho em um plano não termina quando se passa ao próximo plano, mas só termina no final de todo o processo (GARRET, 2011).

\section{Design de games}

De acordo com Teixeira e Gonçalves (2013) a partir de estudos das características de videogames propostas por Jasper Juul (2003), o book app infantil, do ponto de vista da hipermídia pode ser considerado uma narrativa digital que se aproxima dos videogames.

A produção de um game (ou vídeogame) envolve um processo complexo a fim de produzir um resultado eficaz de alto padrão de qualidade. Fullerton (2014), por meio de estudo de metodologias projetuais de engenharia de software desenvolveu um método de produção de game de forma mais flexível e iterativa. As etapas deste processo foram desenhadas em um diagrama na forma da letra "V" , 
contendo as fases de Concepção, Pré-produção, Produção e CA (Controle de Qualidade) (Figura 3).

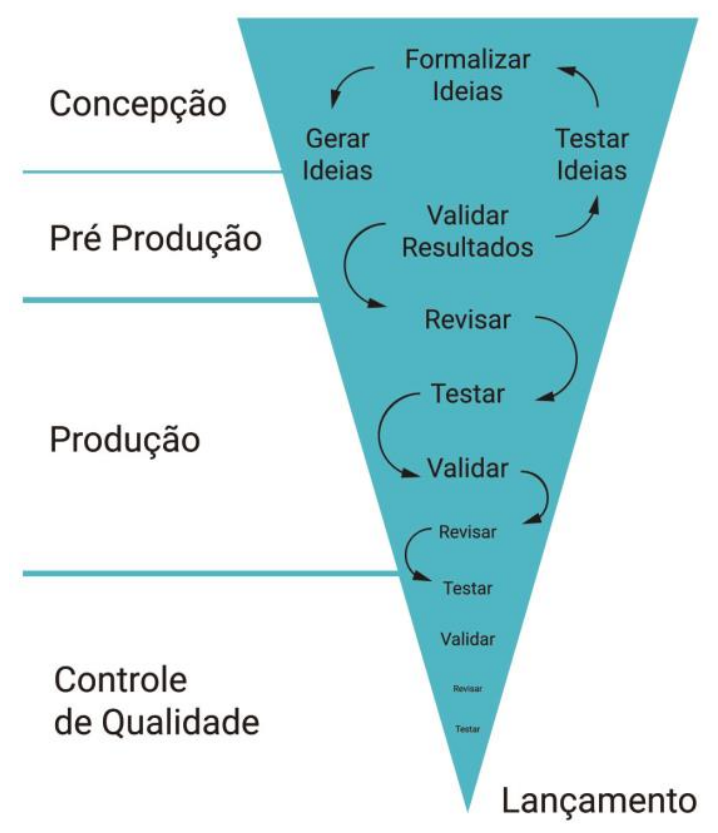

Figura 3: Método iterativo de Design de Games. Fonte: Elaborada pelos autores a partir de Fullerton (2014).

A primeira fase, Concepção, abrange o conceito inicial do projeto com seus objetivos, atributos da equipe de produção, descrição dos recurso necessários, orçamento e cronograma. É importante criar uma agenda que contemple o período de teste, implantação e iteração. O registro do conceito inicial é apresentado em forma de documento. Adams (2013) denomina este documento como High Concept Document, onde é descrito a ideia central do game, o gênero, um resumo da história, a plataforma, os principais objetivos a serem atingidos e o público alvo. As informações devem estar em 2 a 4 páginas e escritas de forma clara para que o cliente compreenda. Esta primeira fase é finalizada com a aprovação do plano, orçamento, ideia inicial e assinatura dos contratos.

Na segunda fase, Pré-produção, a equipe inicia o processo de produção com o refinamento da ideia, apresentação conceitual, tecnologia para produção e implementação do game. Caso a fase de concepção não tenha originado protótipos, este é o momento de desenvolvê-los junto ao design visual e a narrativa. Estes detalhes podem ser organizados de forma colaborativa em um Documento de Design (GDD - Game Design Document). O GDD é um documento que dá continuidade ao conceito do game descrito na fase anterior, apresentando uma visão geral, o posicionamento, público-alvo, plataforma, aspectos mercadológicos, gameplay (jogabilidade), personagens, história, mundo da história e lista de mídias necessárias. Por meio de prototipagens e testes, mediante os requisitos, o game pode ser aperfeiçoado e tecnicamente viabilizado com redução de riscos para desenvolvimento seguro e eficiente nas fases posteriores. Ao final, esta fase entregará um protótipo avançado com progresso tecnológico, planejamento visual, storyboards e plano do projeto atualizado, a fim de ser aprovado pelo cliente/editor e manter o financiamento de acordo com o orçamento inicial.

A fase de Produção é a mais longa e a mais cara do processo. Objetiva executar o que foi estabelecido na préprodução. A medida que o escopo vai evoluindo os recurso necessários para produção vão aumentando. Em um processo iterativo os resultados vão sendo aperfeiçoados e, inevitavelmente, as alterações necessárias afetarão toda a produção. É na produção que os programadores desenvolvem as funções do game, os artistas criam o mundo, os elementos visuais e a animação. Os designers de som criam os efeitos sonoros e temas musicais e os escritores (ou roteiristas) escrevem os diálogos e outros textos necessários. Este processo deve ser conduzido com equipe interdisciplinar, de forma colaborativa e segmentada em procedimentos menores como projetos pequenos dentro de um projeto maior.

$\mathrm{Na}$ fase seguinte, CA (Polimento), o foco passa a ser a qualidade do game de acordo com os objetivos esperados. Assim, os games designers, programadores e profissionais do Controle de Qualidade trabalham juntos para resolver eventuais problemas de tempo, bugs, interfaces e outros problemas. Geralmente $70 \%$ da qualidade de um game é determinada nesta fase, onde é possível garantir uma experiência inesquecível para o jogador. É importante que a equipe de CA crie um documento de teste que mostre todas as áreas, requisitos e condições que o game foi testado.

\section{Procedimentos metodológicos}

A partir da pesquisa bibliográfica realizada investigou-se os processos de design relacionados diretamente com o livro infantil em formato digital interativo.

Ao considerar a herança do design de livro impresso reuniuse conhecimentos de design gráfico e design editorial (AMBROSE E HARRIS, 2011; HASLAM, 2007). Ao considerar o livro em formato digital como uma multimídia interativa reuniu-se conhecimentos do processo de design de experiência do usuário aplicado a hipermídia (GARRET, 2011). E considerando o book app infantil como um aplicativo com características de videogames agregou-se conteúdos de design de games (FULLERTON, 2014; ADAMS, 2013 e CHANDLER, 2012).

Em seguida, por meio de uma análise comparativa verificouse as sincronias entre os procedimentos de design propostos pelas áreas de Design editorial, Design de hipermídia com foco na experiência do usuário e Design de games. Isto posto, elaborou-se uma proposta de fluxo de design com natureza hibrida para o livro digital interativo infantil integrando as respectivas áreas.

A partir deste fluxo iniciou-se 0 um processo de teste por meio da produção de um protótipo de um book app infantil. 


\section{Resultados e discussões}

A integração realizada por meio do referencial citado resultou na configuração de quatro etapas em um fluxo, orientado ela cultura do Design gráfico e editorial. As sub-etapas relacionadas a cada etapa configuram-se em um fluxo iterativo, decorrente do design de hipermídia e design de games (Figura 4).

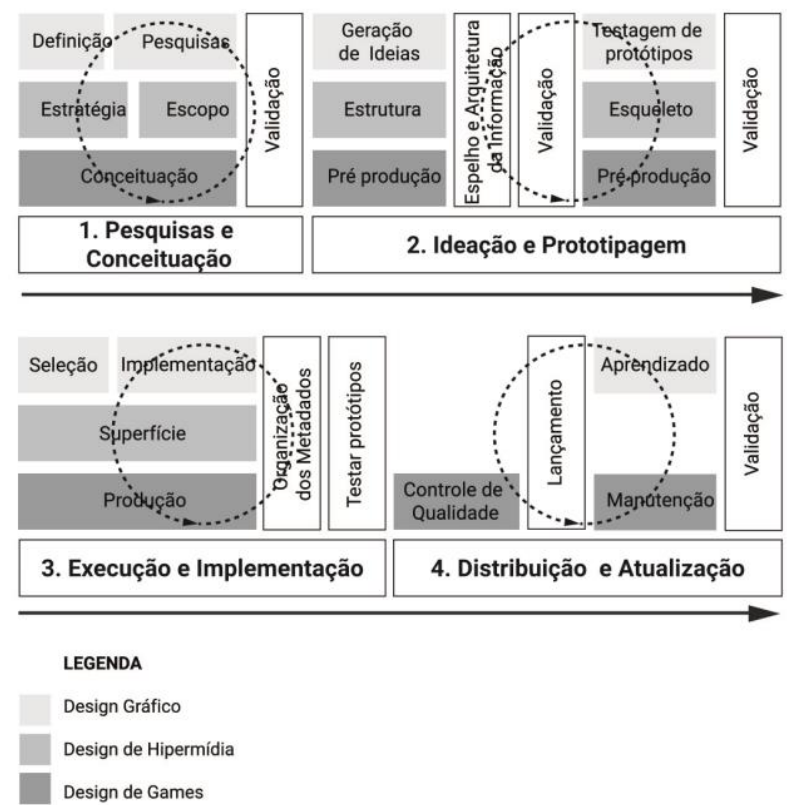

Figura 4: Versão inicial do fluxo para design de livro digital infantil. Fonte: Elaborada pelos autores.

As etapas de cada processo apresentado foram desmembradas e reorganizadas, originando as seguintes etapas e sub-etapas:

1. Pesquisa e Conceituação - Definição, Pesquisa, Estratégia, Escopo, Conceituação e Validação do cliente;

2. Ideação e Prototipagem - Geração de ideias, Testagem de protótipos, Estrutura, Esqueleto, Préprodução, Espelho e arquitetura da informação e Validação da equipe, cliente, stakeholders e público-alvo;

3. Execução e Implementação - Seleção, Implementação, Superfície, Produção, Organização dos metadados e Teste de protótipos;

4. Distribuição e Atualização - Controle de qualidade, Lançamento, Aprendizado, Manutenção e Validação.

A primeira etapa, Pesquisas e Conceituação, começa com o briefing, onde se constrói as diretrizes do projeto a partir do estudo do conteúdo da obra, definição de público-alvo e pesquisas complementares relevantes ao contexto de projeto. Também é o momento de esquematizar o cronograma, as restrições e as necessidades quanto às tecnologias e ferramentas para produção. Após esse caminho percorrido é proposto a validação do mesmo com o cliente para que se tenha mais segurança quanto ao rumo do projeto em relação ao briefing.

A segunda etapa, Ideação e Prototipagem, inicia com a distribuição das cenas junto a uma estrutura de narrativa, storyboard, estudo de personagens, cenários e planejamento das mídias e recursos interativos. Culminando com a arquitetura da informação do aplicativo (livro digital). Neste ponto é possível testar protótipos quanto ao design de navegação e outros aspectos que demandam testagem.

Na terceira etapa, Execução e Implementação, seleciona-se a alternativa gerada que melhor se encaixa na proposta para que seja implementada o design de interface. Usa-se as ferramentas escolhidas para desenvolver 0 aplicativo implementando as multimídias, os recursos interativos e os metadados, ou seja, informações sobre o book app.

$\mathrm{Na}$ quarta etapa, Distribuição e Manutenção, é possível avaliar todo o processo percorrido e agregá-lo como experiência e aprendizado para os próximos projetos. Mesmo após seu lançamento deve-se pensar em um controle de qualidade e manutenção, pois em se tratando de tecnologia os avanços são constantes. A validação também está presente aqui, pois somente com o produto no mercado e sendo usado é que se pode avaliar sua atuação junto aos consumidores.

Como uma evolução do esboço do fluxo já apresentado ele foi reelaborado visualmente para melhor representar o processo descrito (Figura 5). Ainda linear a percepção é de maior flexibilidade, pois as etapas se permeiam em fluxos cíclicos centrados nos objetivos gerais do projeto e de cada etapa. Pode-se voltar e retomar o projeto quando necessário, assim como adaptar os caminhos de cada etapa ao contexto do projeto em questão.

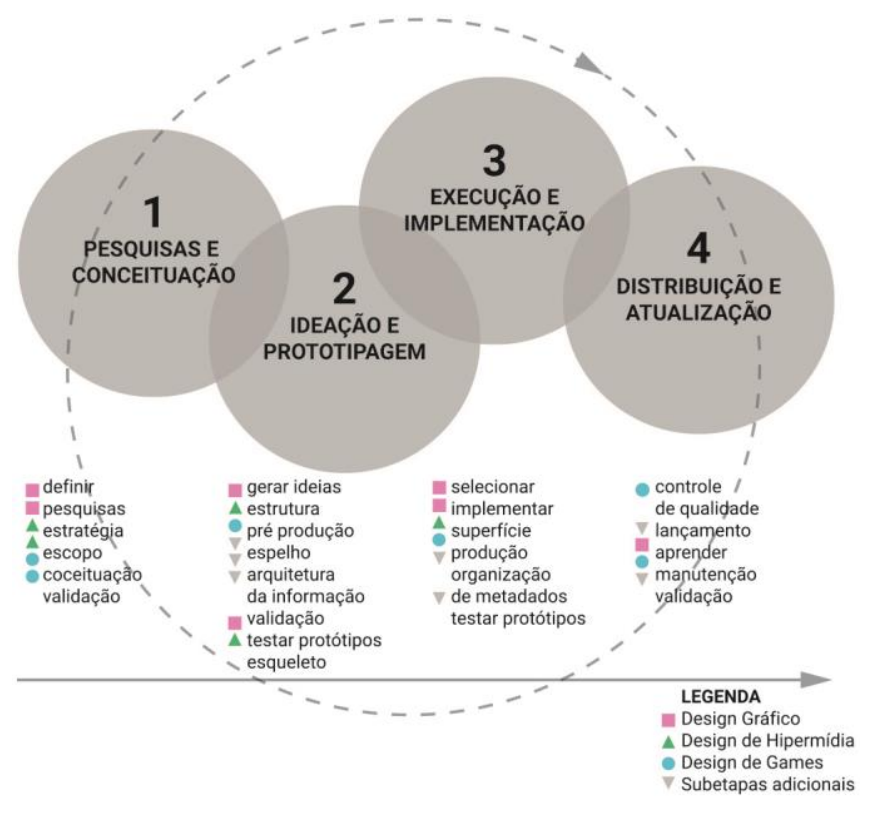

Figura 5: Versão final do fluxo para design de livro digital infantil. Fonte: Elaborada pelos autores. 
A fim de testar o modelo de fluxo proposto para o design de livro digital infantil, iniciou-se uma aplicação em um processo de prototipagem de um book app infantil.

Para isso, buscou-se cessão de um texto literário infantil que pudesse ser utilizado como exemplar neste estudo. O texto proposto foi "O vizinho diferente", escrito por Alexandro Bem. $O$ texto trata-se de uma Literatura de Cordel, gênero literário produzido em versos e popular na cultura nordestina do Brasil. (HOLANDA, 2014).

Na primeira etapa, Pesquisa e conceituação, realizou-se as seguintes sub-etapas:

1. Definição e pesquisa de público-alvo com construção de cenários e personas: o book app desta pesquisa será indicado para crianças na faixa etária de 8 a 10 anos de ambos os sexos. Inseridos na categoria de leitores-em-processo, onde se destaca a presença de texto interagindo com imagens, textos com frases simples, narrativa que gira em torno de um conflito central, estrutura linear (começo, meio e fim) com humor, realismo, imaginário e/ou fantasia (COELHO, 2000).

2. Pesquisa complementar sobre o gênero literário e/ou conteúdo da obra. Neste caso, fez-se um estudo sobre a Literatura de Cordel.

3. Premissas do projeto: foram divididas entre organização de conteúdo, funcionalidades e experiência, tal como tipos de recursos significativos relacionados ao texto.

4. Análise de similares: foram analisados livros interativos infantis premiados e/ou com gênero literário semelhante a Literatura de Cordel.

5. Conceituação: elaboração de uma frase contendo o objetivo do projeto, ou seja, o próprio aplicativo: "Envolver o leitor à narrativa por meio da expressividade das mídias, explorando suas possibilidades de maneira adequada para comunicar a história valorizando seus aspectos cultural e educativo de forma atraente".

6. Escopo (requisitos): a partir da análise dos similares foi elaborada uma relação dos elementos necessários ao projeto do livro digital em questão. Os requisitos foram divididos entre conteúdo, funcionalidade e experiência a partir do ponto de vista de quem praticará a interação.

Na segunda etapa, Ideação e Prototipagem, realizou-se as seguintes sub-etapas:

1. Arquitetura da informação com estrutura de navegação: agrupamento, ordenação e estruturação do conteúdo para que fique claro para o usuário (GARRETT, 2011);

2. Estrutura da história, organização das mídias, recursos interativos e storyboard: para organizar estes itens foi produzido um workshop com participação de pessoas envolvidas na edição e produção editorial - autores, ilustradores, pedagogos e designers. Como resultado foi obtido a divisão das mídias (texto, imagens, som e animação) e dos recursos interativos nas telas (links e botões de navegação) (Figura 6).
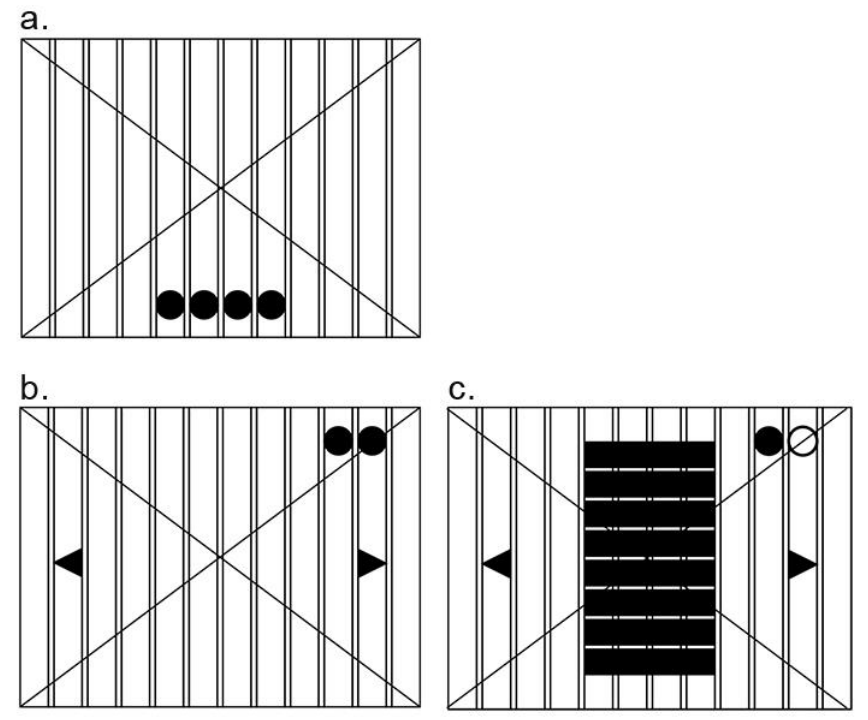

Figura 6: Protótipo inicia do livro digital "O vizinho diferente": a. Tela de introdução com botões: pular, áudio, play e pausa. b. Tela de início da história com botões de navegação. c. Tela de menu com botões de navegação: localização, pausa, play, áudio, idiomas, sobre cordel, informações e personalização. Fonte: Elaborada pelos autores.

Com o desenvolvimento das duas etapas iniciais do fluxo observou-se a adequação deste modelo à complexidade do livro digital interativo infantil, visto que atendeu às necessidades técnicas e conceituais do formato de publicação digital.

O protótipo inicial, resultante da segunda etapa (Figura 6), foi produzido em esquemas - wirefremes, ou seja, uma maneira de mostrar como os principais componentes de interface e interatividade se organizam na tela (GARRET, 2001). Posteriormente, este protótipo será testado juntamente com os recursos visuais, tais como cenários, personagens, animações, botões e links para dar continuidade a esta pesquisa.

O percurso do processo até a última etapa teórica, Ideação e Prototipagem, foi suficiente para demostrar a coerência de fluxo para design de livro digital infantil, pois as etapas seguintes, voltadas para produção do aplicativo, serão resultantes do sucesso destas etapas iniciais.

Ressalta-se que a partir do desenvolvimento da arquitetura da informação, produzido na segunda etapa, há necessidade de constantes prototipagens para testes e validações de navegação e possíveis interatividades. Ações comuns dentro do processo iterativo do design de games. 


\section{Conclusão}

De acordo com a pesquisa realizada no início deste estudo identificou-se o design gráfico e editorial, o design de hipermídia na perspectiva da experiência do usuário e o design de games como três fundamentos necessários para desenvolver um processo de design adequado às tecnologias presentes no livro digital interativo infantil.

Com isso, por meio destas abordagens, correspondentes a estes fundamentos, foi elaborado um modelo de fluxo para design de livro digital infantil que, além de fundamentar o processo produtivo, indicou etapas relacionadas a cada fundamento.

A partir do design gráfico, foi estruturado o fluxo de acordo com o processo clássico de design editorial. Inicialmente, agregando o estudo do público e do conteúdo da obra por meio da documentação originais. Em seguida, foi acrescentado a pesquisa e a análise, a fim de segmentar e hierarquizar as informação para, depois, expressá-las por meio do conceito e geração de ideias.

Ao considerar o livro digital como uma hipermídia, foram utilizados elementos estruturais com enfoque na funcionalidade e usabilidade do produto, na organização da informação e na navegação a partir concepção da experiência do usuário.

Os fundamentos do design de game contribuíram para o fluxo do livro digital por tratarem de tecnologias semelhantes ao design de software. Onde, em cada fase, é possível definir o gerenciamento e a implementação dos requisitos por meio de um processo iterativo de projeto e testes constantes.

$\mathrm{Na}$ etapa final do fluxo, correspondente a manutenção e controle de qualidade, também ocorreram contribuições fundamentais do design de games. Pois assim como os videogames, os book apps necessitam de possíveis correções de erros em seu processamento, atualizações e incrementações decorrentes da evolução tecnológica.

Foi perceptível a contribuição dos fundamentos de cada uma das áreas estudadas para o desenvolvimento de um book app infantil. Ao colocar em prática o fluxo pretendido na primeira etapa de desenvolvimento de um protótipo foi possível fazer correções para unificar os processos que foram diferenciados em um fluxo próprio para esse tipo de projeto.

Com isso, será possível dar continuidade a este estudo utilizando o modelo de fluxo para design de livro digital infantil a fim de dar continuidade a produção do book app utilizado como teste para este processo e assim validar o modelo de fluxo proposto para produção de diferentes narrativas digitais em formato de livro digital interativo.

\section{Agradecimentos}

À CAPES pelo apoio financeiro e ao laboratório Hiperlab/UFSC pela infraestrutura.

Ao CNPq pelo apoio financeiro por meio do PIBIC (Programa Institucional de Bolsas de Iniciação Científica).

\section{Referências}

ADAMS, Ernest. Fundamentals of game design. Pearson Education, 2013.

AMBROSE, Gavin; HARRIS, Paul. Design Thinking. s.m. ação ou prática de pensar o design. (tradução Mariana Belloli). Porto Alegre: Bookman, 2011.

ARAÚJO, Emanuel. A construção do livro: princípios da técnica de editoração. 2. ed. Rio de Janeiro: Lexicon Editorial, 2008.

BALIZA, Emília. Literatura infantojuvenil: contributos para a educação das crianças/jovens com necessidades educativas especiais. In: DE SOUSA, Sérgio Guimarães; MORGADO, Evandro (Organizadores). As Novas Tecnologias e a Literatura Infantil e Juvenil: Cenários e Desafios. Vila Real - Portugal: Edições Vercial, 2014.

CHANDLER, Heather M. Manual de produção de jogos digitais. 2. ed. Porto Alegre: Bookman, 2012.

CHARTIER, Roger. A aventura do livro. São Paulo: unesp, 1998.

COELHO, Nelly Novaes. Literatura infantil: teoria, análise, didática. São Paulo: Moderna, 2000.

FULLERTON, Tracy. Game design workshop: a playcentric approach to creating innovative games. 3. ed. Boca Raton, Florida: CRC press, 2014.

GARRETT, Jesse James. The elements of user experience: user-centered design for the web and beyond. 2 . ed. Berkeley - CA: Pearson Education, 2011.

HASLAM, Andrew. O livro e o designer II: como criar e produzir livros. São Paulo: Rosari, 2007.

HENDEL, Richard. O design do livro. 2. ed. São Paulo: Ateliê, 2006.

HOLANDA, Arlene. Histórias e Histórias. Ceará: Armazém da Cultura, 2014.

JUUL, Jesper. The game, the player, the World: looking for a heart of gameness. In: Level Up: Digital Games Research Conference Proceedings: Utrecht: Utrecht Universit, 2003.

SANTAELLA, Lucia. Comunicação ubíqua: Repercussões na cultura e na educação. São Paulo: Paulus, 2013. 
TEIXEIRA, Deglaucy J. A interatividade e a narrativa no livro digital infantil: proposição de uma matriz de análise. Dissertação (Mestrado) - Programa de Pós-Graduação em Design e Expressão Gráfica, Universidade Federal de Santa Catarina. Florianópolis, 2015.

TEIXEIRA, Deglaucy J.; GONÇALVES, Berenice S. Digital Children's Books: An Analysis of the eBook-app, The
Numberlys from the Perspective of Game Design In: Senses \& Sensibility in Florianópolis: Advertising, Design, Fashion, Marketing, Photography and Visual Culture. Florianópolis: Editora UFSC, 2013.

YOKOTA, Junko; TEALE, William H. Picture Books and the Digital World. The Reading Teacher, v. 67, n. 8, p. 577-585. 2014. 